\title{
Ethnic Aspects of the Formation of a National Idea in the Context of Auto- And Hetero-Stereotypes of Ethnic Groups in Kazakhstan
}

\author{
Lyazzat llimkhanova
}

PhD doctoral candidate, Independent Scientist - researcher, Email:Iyazzat.ilimkhanova@gmail.com

\author{
Mukhan Perlenbetov \\ Doctor of Psychological Sciences; professor and vice-rector of Kainar University; academician of the \\ Kazakh National Academy of Sciences. \\ Email:phd2014.kz@gmail.com \\ Gaziz Telebayev
}

Doctor of Philosophy Sciences; professor of the Kazakh Scientific Research Institute on Problems of the Cultural Heritage of Nomads.

Email: gaziz.telebay@mail.ru

\section{Gulmira Topanova}

Teacher of Pavlodar State Pedagogical University. Email: gulmira.topan@mail.ru

Aynur Sadykova

Master of Psychology. Email: aynur.sadykova@mail.ru

Galiya Abdigalieva

Doctor of Philosophy, Professor of the Kazakh National University after Al Farabi. Email: g.kanaievna@mail.ru

\section{Elnura Adilova}

Master of Social Sciences, KazNU after al Farabi, teacher, elnura.adilova@mail.ru

\section{Doi:10.5901/mjss.2014.v5n20p2656}

\section{Abstract}

The formation of a national idea is a long, complex process, especially in multiethnic and multiconfessional societies. In Kazakhstan, such an idea is not a quick fix but one that will establish over a long period. Concurrently, ethnic context is of special importance in the formation of this idea. In modern times, government plays an important role in shaping this idea. First, the state, by adopting a policy aimed at strengthening inter-ethnic harmony, creates conditions favourable for the formation of a national idea. Second, it creates legal mechanisms to determine the main parameters of this idea in the ethnic sector. Today we are building a new State, a new society, and there is no doubt that in this system of socio-political relations, human consciousness and thinking are kind and, at the same time, a completely new value. First of all, the relationship between the individual and the State, the individual and society should find a completely new content and form, must be based on new features, new principles. In other words, it must be the entity that meet the new values and democratic principles, our way of life and thinking, the requirements of a fair society we seek to build. We tried to take into account the direction of this process is that every citizen, every person on that basis, must determine its attitude towards the development of society and its renewal, your place, if you want your debt. Given our research has helped us to understand the ethnic aspects of formation of national idea in the context of auto and hetero stereotypes.

Keywords: Ethic, aspects, group processes, intergroup relation, stereotypes, multiethnic society, idea, classification, national politics, society, analysis 


\section{Introduction}

Following Hattington's classification, ethnic groups in Kazakhstan can be categorised into different civilisations, such as the Islamic, Orthodox and Western civilisations (Samuel 2000). In this study, we attempt to reveal the values held by these different ethnic groups. According to experts, Kazakhstan's national policy is, in general, carried out consistently and successfully: $16.3 \%$ of experts in this study believe that the main priorities and directions of the national policy are clear and thoughtful, and $45.7 \%$ are inclined to accept such an opinion. However, $38 \%$ of the peer reviews focused on the position of a declarative nature of national politics.

For the purpose of our study, it is very revealing that the contents of the state national policy that experts have identified as the most significant is 'the formation of Kazakh identity' (Strategy of President, 2002). About half (47.3\%) of the experts believe that identity formation is more important than the support for individual ethnic groups, whether they are in majority or minority. Consequently, society has gradually strengthened the overall priority of Kazakhstan's ethnic identity on that which creates an objective basis for the formation of a national idea. According to the president of Kazakhstan, Nursultan Nazarbayev, society should affirm spiritual values based on universal norms of morality, national tradition, civic responsibility and patriotism. Human values, rather than ideological dogmas, are the principles of noninterference in the internal affairs of other states, peaceful settlement of international disputes, territorial integrity, right to life, freedom of speech, conscience, peaceful marches and assemblies, privacy and shelter, tolerance, spiritual continuity and a cultural life of moral purity (President of the Republic of Kazakhstan , 1996).

Another aspect of the problem is whether there is an ontological basis for the formation of a national idea, that is, whether a Kazakh nation actually exists today. In general, the sum of positive ratings is higher than that of the negative ratings. Thus, about one fifth of the experts (21.6\%) hold the most optimistic viewpoint, arguing that Kazakhstan has already formed a nation. Another $31.6 \%$ of the experts argue that the phenomenon of the Kazakh nation is centred more on religious education than social or political considerations. They believe that the nation of Kazakhstan exists at the level of the mentality and culture of Kazakhstan's various ethnic groups because in the process of living together, they all have come to share common spiritual values and traditions (Sofronov, 2006).

Every society defines its own scale of values or the priority for its members. Most often, the main concern is for the material well-being of the state along with taking care of the family, religious adherence, strict observance of rituals and performance of public duties (Limarev, 2001). Furthermore, to function as an ethnic group, the group must constantly update its system of values. According to Pankin, the value system must adjust to the educational system. Targets set in the field of education in any specific historical period give ethnic groups a real opportunity to determine their environment and value orientations, which are contained in the ethnic and cultural sources (Pankin, 2002). Of course, the difference in these positions is very significant; however, they both aim to support the thesis of the existence of the phenomenon of the Kazakh nation, and thus we can assume that more than half of the experts (54.2\%) gave a positive answer. About one fourth (25.8\%) of them are uncertain and believe that the emergence of the phenomenon of the Kazakh nation is possible only through targeted state policy. Experts who lean toward a negative answer to the question of the existence of a Kazakh nation number less than $20.0 \%$. Of these, $13.2 \%$ believe that such a phenomenon does not exist in Kazakhstan and the concept is no more than a convenient tool for the politicians. Such a sceptical view may be owing to either a negative personal experience or theoretical concepts. The remaining $6.4 \%$ of the negative-minded experts believe that in a multiethnic society such as Kazakhstan, the existence of such a phenomenon is impossible in principle. Indeed, the formation of a national idea, including within the context of ethnicity, depends on the efforts of various state and public structures. We have an opportunity to evaluate this process on the basis of the opinions of the experts surveyed in this study.

The most effective factor as recognised by the experts is the President's activities aimed at consolidating the Kazakh society. As Nazarbayev said, 'We have an inexhaustible spiritual wealth'. The most significant value according to the president is patriotism. Patriotism is the highest value for any ethnic group. Speaking of this multiethnic state, the president points to patriotism, which manifests in one's love for the country. According to Nazarbayev, the most important and crucial dimension to any state is agreement, peace and stability. We can say that Kazakhstan is very happy as its territory is inhabited by over 130 representatives of 46 ethnicities and faiths, which have strong support in maintaining peace in our country. In this respect, the Kazakhs are true to the covenant of the $21^{\text {st }}$ century genius Abaya, 'Love all mankind as brother', and will continue to adhere to this principle (Speech of the President of the Republic of Kazakhstan, 2005). A total of $85.6 \%$ respondent gave positive responses, believing that the President is putting forward maximum efforts for the consolidation of society and formation of common Kazakh values, and that this work will achieve its goal. Other authorities received much less positive ratings. For example, positive responses summed up to $41.8 \%$ for the government, $40 \%$ for the Assembly of Peoples of Kazakhstan, $37.4 \%$ for local government offices and $35.2 \%$ for national 
cultural centres. It turns out that at present, the consolidation of society, formation of the Kazakh nation and emergence of a national idea depends primarily on the highest official of the state. Given this state of affairs in a democratic society, it is difficult to recognise what is normal. The task at hand is to enhance the efforts of civil society and its institutions for the consolidation of the country's various ethnic groups.

Opposing viewpoints also emerge on the issue of whether the formation of a national idea should be accompanied by any documents (e.g. laws, concepts, codes) or occur in a natural mode of 'folk art'. According to experts, more specific documents are needed, which should reflect the principles of the state national policy (72\%). Of course, it would be naive to expect that one document can generate a national idea; in fact, it is hardly even conceivable given the social awareness of the value of decrees or laws. At the same time, we cannot rely on spontaneity and naturalness in the process, and the state should promote national values by all available means. Meanwhile, the conceptual problem of the formation of a national idea has been the subject of attention not solely in the Presidential Address to the Nation. A similar target was set in the concept of the national identity formation of the Republic of Kazakhstan, adopted in 1996.

In the formation of a national idea in a multiethnic society, it is possible to use two main strategies based on either the national values of the state-forming ethnic groups or the integral values that comprise of all positive values of the major ethnic groups of the country. The ethnic situation in Kazakhstan does not allow the first strategy. For example, the opening line of the nation's first constitution, 'We the people of Kazakhstan...', provoked a vehement reaction from the representatives of the Slavic ethnic groups.

The choice of the second strategy involves the analysis of the basic values that may be common to all ethnic groups residing in Kazakhstan. In one study, 2002 respondents were asked about what they could call their dream. The distribution of responses according to the respondents' ethnicities reveals important findings. First of all, it is possible to judge the proximity of the value orientations of the nation's various ethnic groups. According to Lure, the preference values are largely determined by historical destiny and cultural tradition. Thus, every single person can theoretically take any value, although in practice, the choice is determined to a large extent by the nature of his upbringing, education and experience. This choice is not determined by human genetics (Lure).

\section{Survey Results}

Thus, among all respondents, 'to be healthy' was cited as the most aspired dream by $27.7 \%$ of Uzbeks and $44.8 \%$ Uighurs (Table 1). It was also a fairly popular choice as a second or third most important dream. The second most popular dream was 'that our country and the world will always have peace and no wars or disasters', and the third was to 'earn big money'. The only exception was that the Uighurs report the dream to 'earn big money' as the second most important and world peace as the third important choice.

The choice of these values is very understandable and justified, because health has always occupied a special place in the national mentality of the people.

[Table 1]

In today's challenging environment, the need for health seems particularly acute. The desire for peace and stability, crystallised in the public consciousness for centuries is also one of the most preferred values. Finally, the movement of the market too has its influence into the realm of consciousness.

Thus, values that are supported by all major ethnic groups in the country are the values of health, peace and material prosperity. These can become, in our view, the base for the formation of a national idea. In this case, the national identity should be constructed on three pillars: (1) citizens' health, (2) social peace and stability and (3) public welfare. The national idea can be formulated in this way and made understandable to the people as well as can be supported by the majority ethnic groups.

For a national idea to emerge, it is very important to first examine what constitutes the stereotypes among the main ethnic group and other ethnic groups in the country.

One indicator of inter-ethnic relationships is a willingness to live in countryside, which is home to many nationalities. The Western social psychology has mainly studied components such as inter-ethnic relationships, which are connected with the 'depth' and 'duration' of the contact between groups. The role of inter-ethnic relationships in the formation and functioning of stereotypes can be understood only by the nature of these relationships in their socially determined form: cooperation or competition and dominance or submission. The nature of the relationship depends on the direction and degree of favorability of stereotypes; however, with a substantial change in the nature of relationships between these parameters, the old stereotypes can be overturned (Stefanenko, 1987).

Most of the interviewed representatives of ethnic groups showed tolerance and lacked ethnophobia. For example, $81.9 \%$ of Kazakhs and up to $96.4 \%$ of Uighurs opposed the view that we must live in an ethnically homogeneous environment or 
declared that it did not matter.

However, it would be wrong to conceal the existing distance between ethnic groups. In Kazakhstan, for example, it is generally believed that the national policy is specific to all ethnic groups in the country, but Germans, Uighurs and Russians were more likely than members of other ethnic groups to express the opinion that the current national policy aims to support one ethnic group. At the same time, most Kazakhs and Uzbeks believe that the national policy does not support the interests of only the indigenous ethnic group.

The ethnic groups reported that they would respond differently in the case of ethnic conflict. Russian, Koreans, Germans and Ukrainians marked the option 'try to leave the country' four to nine times more than did the Uighurs, Uzbeks and Kazakhs.

One measure of ethnic distance is related to mixed marriages. According to Lederer and Jackson, a good marriage is characterised by the following features: tolerance, respect for each other, honesty, desire to be together and similar interests and values (Lederer and Jackson, 1968). Family stability also contributes to the ability of family members to avoid conflicts and to negotiate on all aspects of life together.

Conflicts occur between people in connection with the decision of issues in their social and personal lives (Likson, 1997; Solovev, 1997). The most tolerant in this respect were the Koreans of Kazakhstan: $50 \%$ viewed inter-ethnic marriages as positive, $27.8 \%$ as neutral and only $5.6 \%$ as negative. Furthermore, a positive attitude toward inter-ethnic marriage also prevails among Germans, Ukrainians and Russians. In contrast, Kazakhs, Uighurs and Uzbeks hold a critical attitude to this phenomenon.

It is common knowledge that ethnic distance is largely determined by language barriers. As a rule, a foreign language on its own, if it does not have specific positive or negative associations, has psychologically neutral impact. Prejudice and hostility toward a language are owing to unpleasant memories associated with inter-ethnic contacts. Many representatives of national minorities avoid speaking in their native language in public places, knowing that it can be displease other ethnic groups. At the same time, members of many ethnic groups openly speak in their native language without any regard for the degree of the intensity of inter-ethnic relationship (Ideal-Globalization).

In Kazakhstan, on the one hand, language barrier is minimal because a vast majority of the population is fluent in Russian. On the other hand, however, ethnic groups are divided into two groups by the degree of state language proficiency. The first group includes Russians, Germans and Ukrainians, $50 \%$ of whom do not speak Kazakh. The second group consists of Koreans, Uighurs, Uzbeks and Kazakhs, 30\%, 10.7\%, 2.2\% and 2.1\% of whom respectively do not speak Kazakh. These and other factors will definitely influence the formation of a national idea. To truly become a national idea, an idea must be adopted by most of the society members. In the investigated vein, it is important that this idea was adopted by most of the ethnic groups and diasporas in Kazakhstan, and within them, the greater part of their representatives. In many ways, adoption of a national idea will be determined by whether representatives of the ethnic groups feel Kazakhstan to be their homeland. Naturally, most Kazakhs nationwide are open to this idea: $97 \%$ of them referred to Kazakhstan as their homeland, a percentage just behind the Uighurs (96.4\%). Among the Uzbeks, 91.1\% believed that their homeland is Kazakhstan. However, the percentage of people with such identification among other ethnic groups is much smaller.

Among the Russians, for example, $67.4 \%$ named their 'homeland' as Kazakhstan or their city of residence, the region where they live now (Volkogonova, 2001). However, 18.5\% of them refereed to Russia, the land of their ancestors or the place of their nationality, as their homeland. Furthermore, $11.9 \%$ of Russians took a neutral stand, naming the USSR as their homeland while 1.5\% named CIS. The other ethnic groups, Ukrainians, Germans and Koreans, also reported similar identification ratios. Comparing the results, such identification results in repulsion of the 'neighbours' in the development of common stereotypes, and it is a myth that becomes the basis for the interpretation of social events, whether it is a common myth about 'blood and soil' or of the 'mysterious Russian soul'. Therefore, In Kazakhstan, Turkicspeaking ethnic groups today are more willing to accept the idea of a national idea than Slavic and other groups.

In the analysis of the national idea, it is important to know about the basic characteristics of the ethnic groups that have this national idea (in our opinion, the national elite, primarily, should be engaged in the formation of the national idea).

In this study, we analyse the main characteristics of a state: ethnic Kazakhs, with the aim of identifying a national idea around which to rally the nation. We used sociological data obtained in November and December 2008 by the Public Fund Center for Ethnopolitical and Humanities Research that worked for the Ministry of Culture and Information.

First, let us turn to the quantitative indicators of ethnic stereotypes. Ethnic stereotype, being a form of social stereotype, has all the properties of the latter and differs only in content (Platonov, 2000). It should be noted that the image of Kazakhs, the resulting analysis of sociological material, looks very concentrated. Of the 15 properties offered by respondents to choose from, only 7 (for self) and 8 (when evaluating other ethnic groups) have received significant 
support of the respondents, more than $5 \%$. This means that the Kazakhs have, for themselves and for other ethnic groups, a rather pronounced, well-rounded appearance: they are sufficiently 'recognised' with no 'blurring' features. Thus, it seems easier to consolidate the nation around the state-forming ethnic image of the Kazakh.

In this case, since the survey was conducted not by the method of binary oppositions but by the method of a list of specific qualities, the little quantification of qualities is also characterised by the ethnic group. For example, the Kazakhs' self-assessment (auto-stereotypes) did not include, or included only to a very small degree, the characteristics of 'cunning', 'frugal' and 'intolerant'. These are all negative qualities, and their absence is related to ethnic self-esteem. However, the objective of this assessment can be confirmed by not only examples from life or literature but also the attitude of other nationalities (hetero-stereotypes). The above negative qualities were also among the least distinguished by the surveyed members of other ethnic groups, including Russian, Ukrainians, Uzbeks and Uighurs.

We now turn to the analysis of separate auto-stereotypes of the Kazakhs. The highest expressions were two qualities that are considered inherent in nearly two-thirds of the respondents: 'love' and 'culture'. Both the qualities are positive evidence of high self-esteem among this ethnic group and their confidence in future. Furthermore, both the qualities are ahead of others by two or more times, indicating their special significance in self-ethnicity. Peacefulness should be interpreted probably as a basic concept of the relationship to the loved ones and the world, and even members of other ethnic groups. This is a favourable factor for the formation of the national idea based on a single country, a common territory and a single state. That love of peace, harmony and good neighbors can be the basis for the national idea as can be seen from the fact that these features also appears in the main self-assessment and evaluation of Russians and Uzbeks.

The term 'cultural' in this context means, in our opinion, more 'educated' (Kazakh children generally receive a higher education). However, it is necessary to pay attention to the presence of a healthy self-critical attitude of Kazakhs. Thus, at the third and fourth places in the hierarchy of qualities, they put the negative qualities of 'jealous' and 'powerhungry'.

In the first case, we are talking about envy, that is, inability to enjoy the success of one's neighbour, denial of support and lack of reciprocity. On the one hand, negative quality of people has been criticised by the great Abaya, and it can be interpreted as an incomplete formation of ethnicity or its lack of fragmentation.

On the other hand, Western societies show at least a significant manifestation of this social quality, which is ultimately the impetus for social mobility. At the same time, today's relationship in the system of political recruitment in Kazakhstan, called the 'chief-client' relationship, seems to significantly contradict the stereotype of a lack of support for each other. Recognising the need for a more in-depth study of the national character, we note the inconsistency of the actual characteristics of the Kazakhs.

Another quality, which also has a visible socio-political connotation, is 'lust for power'. In this case, it is just the desire for power, to take a position, to be 'with a briefcase' and to command resources. The objectivity of the Kazakh respondents is supported by the fact that these negative qualities were mentioned by both the dominant and other ethnic groups. However, there is a characteristic difference: other Kazakh nationals are reportedly still more 'power-hungry' than 'envious'.

The top five most common characteristics include 'reliable'. This trait was selected by both Kazakhs and other ethnic groups. We have already mentioned the qualities that are thought to be the least inherent in Kazakhs: being cunning, mean and intolerant. Apart from these, traits that scored a small percentage include 'religious', 'hardworking' and oddly enough 'generous'.

There appears to manifest such a feature of the human psyche as the consideration of phenomena in comparison, especially the phenomena of the same order. Assessing the quality of some people, consciously or unconsciously compare it with the severity of a particular ethnic group, and then say it. For example, in regard to religiosity, the Kazakhs noted Ukrainians and Uzbeks as more religious, almost 10 times more, than all other ethnic groups. Regarding diligence, it must be remembered that 'everything is relative': Uighurs are perceived as having more qualities of Kazakhs and Uzbeks are in the second place. Kazakhs believe that they are more generous than others, especially than Uzbeks and Uighurs.

We now turn to the analysis of hetero-stereotypes of the Kazakhs. Ethnic stereotypes are divided into auto- and hetero-stereotypes. Auto-stereotypes are images of one's own people including opinions, judgments and assessments, and are mostly positive. Auto-stereotypes often function to raise and maintain a sense of patriotism. For these purposes, certain techniques are used, such as searching for a common divine ancestor, attempting to push the ethnic origins far back in history and maintaining a cult of national heroes, both real and fictional. Hetero-stereotypes, on the other hand, are the assessment of an ethnic group by others. Hetero-stereotypes are much less friendly. The main point of such stereotype is the so-called 'complex foreign-strangeness', implying that a member of another ethnic group is not only 
'different' but also 'strange' (Chernyavskaya).

First, on the average, hetero-stereotypes of Kazakhs are very close to their auto-stereotypes, indicating a high degree of objectivity of the ethnic group. The generalised image of Kazakhs in the eyes of other ethnic groups is formed from such qualities as the following: peaceful, cultural, power-hungry, robust, envious, respecting the senior and independent. This quality was reported by more than $10 \%$ of respondents. As can be seen, it is dominated by positive qualities (5 of 7). Therefore, the country's ethnic groups largely have a positive attitude toward Kazakhs, which is certainly a key factor in the formation of a national idea.

Of course, one must consider and 'claim' the other ethnic Kazakhs. They are centred on the definition of 'powerhungry', a quality that can be, in our opinion, interpreted in the context of dissatisfaction with their representation of other ethnic groups in power. Despite the attempts of authorities to comply with certain conditions, the mass consciousness (as a 'container' stereotype) comes probably from the need to strictly proportionate the presence of the other ethnic groups in power according to their proportion in the population. However, the mechanical principle of proportionality is not in the paramount public interest.

If the general attitude of other ethnic groups can be regarded as prevalent in a positive manner, then the estimates of individual ethnic groups can detect certain distance that exists between them and Kazakhs. In Russians, such distance (most likely due to the syndrome of being 'big brother' who brought civilisation to the steppes) is seen in the fact that although they have noted 'culture' as the quality of the Kazakhs in the second place, its quantitative expression is less than other ethnic groups. Consequently, less than other Russians, Kazakhs consider culture (educated). Furthermore, Ukrainians are at a certain distance from Kazakhs, who consider Kazakhs as highly 'power-hungry' and less 'reliable' than other ethnicities. Uzbeks as well have ethnic distance from Kazakhs, as was expressed by the dominance of such responses as 'imposing their own customs'. This is most likely due to the cultural and linguistic proximity of Kazakhs and Uzbeks, when the latter feel the danger of assimilation by the dominant ethnic group. Alienation in Uighurs, however, appeared to be much less than in other ethnic groups, and they emphasised the Kazakhs as 'peaceful'.

\section{Acknowledgments}

Our main task was to conduct qualitative research with involvement of specialists on the theme study. First of all, we would like to express our gratitude to Dr. Perlenbetov Mukhan and independent researcher of psychological Sciences Lyazzat llimkhanova. Their invaluable experience which has helped us to achieve results in this study. Would like to thank all the participants for attending and we believe such research in the field of formation of national idea could become a model for future research of young scientists.

\section{Conclusion}

Given the positive image of the Kazakh ethnic group in both auto- and hetero-stereotypes, one can confidently assume the presence of the basic conditions for the formation of a national idea in Kazakhstan. Consolidation, as noted by Tishkov, is the fusion of similar languages and cultural groups into a larger ethnic community, or the inclusion of ethnic community groups close to it (Tishkov, 1989). Moreover, its main contents will most likely be the concept of a single country that is able to assimilate ethnic groups and in turn stimulates a sense of responsibility toward the country.

The consolidation of Kazakhstani society is the basic position of our country, which already has a strong position. The question of forming a national idea will remain, given the general psychology and the common aspiration of all ethnic groups of Kazakhstan according to their view and understanding of the world and humanity. We are devoted to the analysis of ethnic stereotypes in Kazakhstan in the context of a national idea. The positive image of ethnic Kazakhs, both in auto- and hetero-stereotypes, allows us to assume with confidence the presence of the basic conditions for the formation of a national idea. Its basic maintenance becomes, most likely, the concept of 'one country', an idea that is capable of uniting various ethnic groups and in turn stimulating the feeling of responsibility for the country in everyone.

\section{References}

Chernyavskaya, Y. 'Folk culture and national traditions', Chapter 1. What is an 'ethnicity'? 'Ideal-Globalization', E-book Planetary Psychology Book Project.

Lederer, W.J. and Jackson, D.D. (1968) The Mirages of Marriage (New York: W. W. Norton) 116-117.

Likson, C. (1997) 'Conflict', Seven Steps to the world, St. Peter Publishing, 592.

Limarev, V.N. (2001) 'The theory of "ethnogenesis." Part 1', 18 December. 
Lure, S. 'Historical ethnology', A manual for schools.

Pankin, A.B. (2002) 'Design national and regional educational systems on the basis of ethnic and cultural connotations', Elista.

Platonov, J.P. (2000) 'The peoples of the world of geopolitics in the mirror (the structure, dynamics, behaviour)', Ethnic stereotypes of behaviour textbook (Spb. Univ of St. Petersburg. University Press).

President of the Republic of Kazakhstan, 23 May 1996, N 2995. 'On the concept of national identity formation of the Republic of Kazakhstan', Electronic resource: http://online.zakon.kz/Document/?doc id=1005634\&sublink=1.

Samuel, L.H. (2004) 'Who are we'? The challenges of America's national identity, Scientific and popular edition. Publisher: AST (Tranzitkniga).

Solovev, N.Y. (1997) Marriage and Family Today (Vilnius: Mintis) 226.

Sofronov,a L.A. (2006) 'About the problems of identity', Culture through the lens of identity, M. Indrik, 8-24.

Speech of the President of the Republic of Kazakhstan, Nursultan Nazarbayev at the III World Kazakh Meeting, Astana, 29 September 2005. Electronic resource: http://www.rusnauka.com/12_KPSN_2012/Politologia/3_108636.doc.htm

Stefanenko, TG. (1987) 'Social stereotypes and interethnic relations', in Communication and optimizing collaborative activities (ed.) G.M Andreeva, J. Yanousheka (Moscow, Moscow Univ. Press) 242-250.

Strategy of President from 26 April 2002, N 856. Kazakhstan People's Assembly Strategy for the Medium Term.

Tishkov, V.A. (1989) Essays on the theory and the politics of ethnicity (Moscow: Nauka).

Volkogonova, O.D., Tatarenko, I.V. (2001) 'Russian Ethnic identification, or the temptation of nationalism', 10, 2, $149-166$. 